Article history

Received Okt 30, 2020

Accepted May 29, 2021

\title{
PEMBUATAN PETA PORTABEL USAHA KERAMBA BUDIDAYA IKAN BERBASIS ANDROID SMART PHONE DI SEPANJANG SUNGAI MARTAPURA KOTA BANJARMASIN
}

\author{
Faris Ade Irawan', Effan Najwaini ${ }^{2}$ \\ ${ }^{1}$ Program Studi Geodesi, Politeknik Negeri Banjarmasin, Jl. Brigjen H. Basri kayu Tangi Banjarmasin, \\ 70123, Indonesia \\ ${ }^{2}$ Program Studi Manajemen Informatika, Politeknik Negeri Banjarmasin, Jl. Brigjen H. Basri kayu Tangi \\ Banjarmasin 70123, Indonesia \\ email: faris.irawan@poliban.ac.id,effan@poliban.ac.id
}

\begin{abstract}
Smartphones that we have are equipped with various android-based applications that are distributed free of charge but are very useful and can be used optimally if we know how to use them, one such application is the Carrymap Observer. This application allows us to display maps offline on a smart phone but can integrate with GPS and can be manipulated by users directly. We make portable maps according to the theme we want which will be accessed on andoid smart phones that we have using Arc GIS devices so that they can be used anytime, anywhere as needed. Banjarmasin is also called the City of Thousand Rivers, a city that has many rivers, both large and small. Martapura River is one of the largest rivers and divides through the city of Banjarmasin. Banjarmasin City residents utilize the Martapura River as an economic and transportation center. on the banks of the River Martapura lined cages owned by residents. The floating net boxes are in groups. There are dozens, some are only a few. The farmers raise several types of fish. The majority of catfish and pomfret. The existence of these cages needs to be inventoryed to make it easier to monitor so that the good and bad impacts that are directly related to these business activities can be managed and monitored by related parties. From this research, a portable map based on Android smart phone is produced, it is offline and can be operated quickly via a smart phone anytime and anywhere. provide information about ownership, types of fish being cultivated and other information deemed important. Based on researchers' searches on Google Scholar, no similar studies were found, namely the theme of making portable maps of floating fish cages along the Martapura River in Banjarmasin. So this research needs to be done in order to add to the literature and references to support further research, because there are many benefits that we can get from the portable maps produced, the creation of a database of floating aquaculture and the application of science in the field of geospatial.
\end{abstract}

Keywords: Android smart phone, portable map, floating fish cages.

\begin{abstract}
Abstrak
Smart phone yang kita miliki dilengkapi dengan berbagai aplikasi berbasis android yang dibagikan secara gratis tetapi saangat bermanfaat dan dapat digunakan secara maksimal jika kita mengetahui cara penggunaannya, salah satu aplikasi tersebut adalah Carrymap Observer. Aplikasi ini memungkinkan kita menampilkan peta secara offline di smart phone tetapi dapat berintegrasi dengan GPS dan dapat dimanipulasi oleh penggunanya secara langsung. Kita membuat peta portabel sesuai tema yang kita inginkan yang akan diakses pada andoid smart phone yang kita miliki menggunakan perangkat Arc GIS sehingga dapat digunakan kapanpun, dimanapun sesuai keperluan. Banjarmasin disebut juga Kota Seribu Sungai, merupakan kota yang banyak dialiri sungai-sungai baik besar maupun kecil. Sungai Martapura adalah salah satu sungai terbesar dan membelah mengaliri Kota Banjarmasin. Masyarakat Kota Banjarmasin memanfaatkan Sungai Martapura sebagai pusat ekonomi dan transportasi. di tepian Sungai Martapura berjejer keramba milik warga. Kotak-kotak jaring yang mengapung itu berkelompokkelompok. Ada yang puluhan, ada juga yang hanya beberapa. Para petaninya membudidayakan
\end{abstract}


beberapa jenis ikan. Mayoritas patin dan bawal. Keberadaan keramba tersebut perlu di inventaris agar memudahkan dalam monitoring sehingga dampak baik dan buruk yang berhubungan langsung dengan kegiatan usaha tersebut dapat dikelola dan dipantau oleh pihak terkait. Dari penelitian ini dihasilkan peta portabel berbasis android smart phone, bersifat offline dan dapat dioperasikan melaui telepon pintar (smart phone) secara cepat kapan saja dan dimana saja. memberikan informasi tentang kepemilikan, jenis ikan yang dibudidayakan dan informasi lainnya yang dianggap penting. Berdasarkan penelusuran peneliti di Google Cendekia, tidak ditemukan penelitian sejenis, yaitu tema pembuatan peta portabel sebaran keramba apung budidaya ikan disepanjang Sungai Martapura di Banjarmasin. Sehingga perlu dilakukan penelitian ini agar menambah pustaka dan referensi untuk menunjang penelitian selanjutnya, karena banyak manfaat yang bisa kita dapatkan dari peta portabel yang dihasilkan, pembuatan basisdata usaha budidaya keramba ikan apung dan penerapan ilmu pengetahuan dibidang geospasial.

Kata Kunci: Android smart phone, Peta portabel, Keramba ikan apung. 


\section{PENDAHULUAN}

Kebutuhan informasi dalam bentuk peta sangat berkembang pesat seiring dengan kemajuan teknologi telepon pintar atau smart phone. Masyarakat sudah sangat familiar dengan peta dan hampir semua pengguna smart phone dengan memudah membaca peta karena sudah tersedia perangkat penunjang untuk mengoperasionalakan peta tersebut. Untuk memaksimalkan perangkat atau gadged yang kita miliki, kita sebagai pengguna harus mengetahui dan memanfaatkan smart phone yang kita miliki. Smart phone yang kita miliki dilengkapi dengan berbagai aplikasi berbasis android yang dibagikan secara gratis tetapi saangat bermanfaat dan dapat digunakan secara maksimal jika kita mengetahui cara penggunaannya, salah satu aplikasi tersebut adalah Carrymap Observer. Aplikasi ini memungkinkan kita menampilkan peta secara offline di smarth phone tetapi dapat berintegrasi dengan GPS dan dapat dimanipulasi oleh penggunanya secara langsung.

Tujuan penelitian ini adalah pembuatan peta portabel berbasis android smart phone, bersifat offline dan dapat dioperasikan melaui telepon pintar (smart phone) secara cepat kapan saja dan dimana saja. memberikan informasi tentang kepemilikan, jenis keramba, jenis ikan yang dibudidayakan dan informasi lainnya yang dianggap penting.

Berdasarkan penelusuran peneliti di Google Cendekia, tidak ditemukan penelitian sejenis, yaitu tema pembuatan peta portabel sebaran keramba apung budidaya ikan disepanjang Sungai Martapura di Banjarmasin. Sehingga perlu dilakukan penelitian ini agar menambah pustaka dan referensi untuk menunjang penelitian selanjutnya, karena banyak manfaat yang bisa kita dapatkan dari peta portabel yang dihasilkan, pembuatan basisdata usaha budidaya keramba ikan apung dan penerapan ilmu pengetahuan dibidang geospasial.

\section{METODE PENELITIAN}

Penelitian ini dilakukan di Kotamdaya Banjarmasin, Ibu Kota Provinsi Kalimantan Selatan. Secara astronomis kota Banjarmasin terletak di antara $03^{\circ} 15^{\prime} 00^{\prime \prime}-03^{\circ} 22^{\prime} 00^{\prime \prime}$ LS dan $114^{\circ} 32^{\prime} 00^{\prime \prime}$. Kota Banjarmasin terkenal dengan sebutan Kota Seribu Sungai karena banyak memiliki jaringan sungai baik sungai kecil maupun sungai besar, salah satu sungai besar yang dijadikan obyek penelitian ini adalah Sungai Martapura.

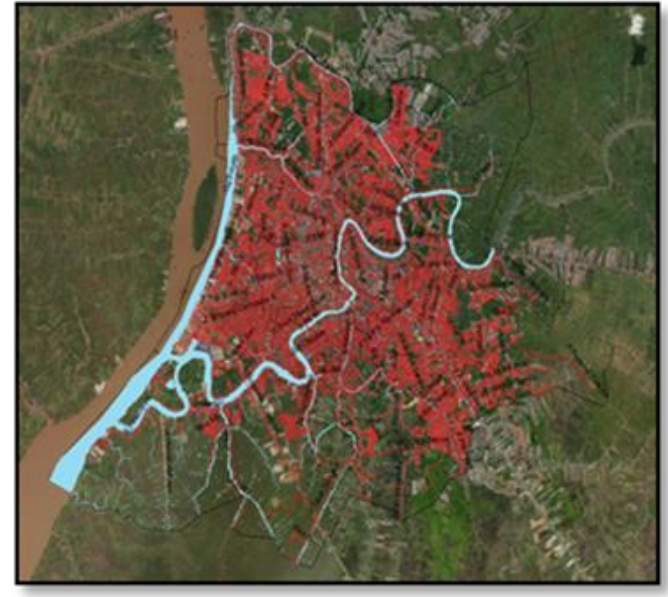

Gambar 1. Peta Dasar Jaringan Jalan dan Sungai Kota Banjarmasin

Ada beberapa proses utama yang dilakukan pembuatan peta portabel ini :

- Koreksi Radiometrik dan Geometrik citra satelit

- Proyeksi citra satelit

- Pembuatan jaringan jalan melaui proses digitasi citra satelit

- $\quad$ Survey lapangan dengan metode sensus menggunakan GPS Handheld

- Pengolahan data

Pengolahan data secara rinci adalah :

- Desain database data atribut keramba apung yang merupakan data non spasil penelitian ini

- Penggabungan (join) data spasial dan non spasial.

- Konversi data sesuai format (extention)aplikasi CarryMap

- $\quad$ Pengujian aplikasi, seperti gambar 2.

\section{HASIL DAN PEMBAHASAN}

Penelitian ini menghasilkan peta tematik dengan judul Persebaran Keramba Budidaya Ikan Apung Berbasis Android Smart phone Di Sepanjang Sungai Martapura Kota Banjarmasin. Peta tematik merupakan peta yang hanya menyajikan data-data atau informasi dari suatu konsep/tema [1]. Peta ini disajikan dalam bentuk digital dan dioperasikan menggunakan perangkat smart phone (telepon pintar) dengan system operasi berbasis android. Peta tersebut dapat digunakan kapan saja dan di mana saja sesuai keperluan pengguna, dengan kata lain penelitian ini menghasilkan peta portable. Smartphone adalah sebuah perangkat yang memungkinkan 
untuk melakukan komunikasi juga di dalamnya terdapat fungsi PDA (Personal Digital Assistant) dan berkemampuan seperti komputer [2].

Menurut KBBI Kemendikbud yang diakses menggunakan mesin pencarian secara online [3] , arti kata Portabel adalah mudah dibawa-bawa dan mudah di jinjing. Peta portabel akan dapat dengan mudah dibuat dan disajikan pada perangkat android smart phone jika memiliki 2 jenis data yaitu data spasial dan non spasial [4]. Informasi yang disajikan pada peta tersebut adalah jaringan jalan dan sungai di Kota Banjarmasin serta persebaran lokasi tambak ikan lengkap dengan atribut keterangan yang berkaitan dengan tambak ikan tersebut. Atribut peta yakni informasi yang disajikan merupakan data sensus lapangan di lokasi-lokasi tambak ikan yang terdapat di sepanjang sungai Martapura Kota Banjarmasin yang dilakukan pendataan di tahun 2019.

Peta portabel yang dihasilkan dapat dijalankan menggunakan aplikasi CarryMap yang merupakan aplikasi gratis yang disediakan oleh AppStore. Carrymap adalah aplikasi tambahan yang dikeluarkan oleh ESRI yang berfungsi untuk mereproduksi data yang telah dibuat dengan software ArcGIS sebagai peta mandiri tanpa aplikasi peta elektronik yang dapat di buka di desktop PC, Windows Mobile, Apple IOS dan android [5]. Extention Carry Map adalah corel metafile $\left({ }^{*} \mathrm{cmf}\right)$, sehingga ukuran keberhasilan penelitian ini adalah membuat meta data yang dapat dijalankan pada program tersebut. Pada gambar di bawah ini merupakan peta portabel yang berhasil dibuat dan dapat dijalankan pada perangkat smart phone kita.

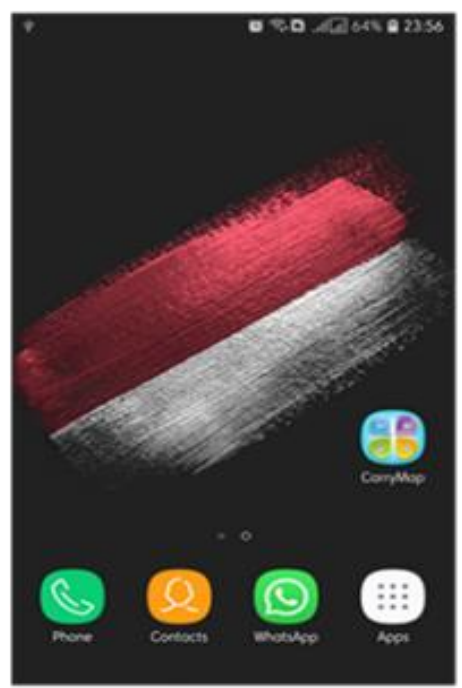

Gambar 2. Pengujian aplikasi yang telah di unduh melalui appstore

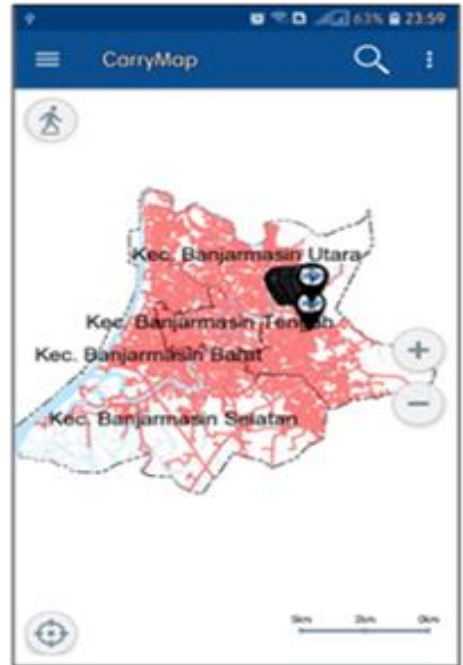

Gambar 3. Tampilan awal peta portable

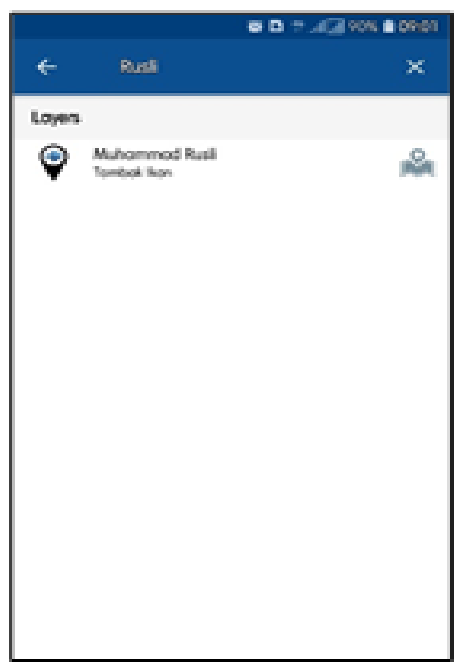

Gambar 4. Pencarian berdasarkan nama pemilik

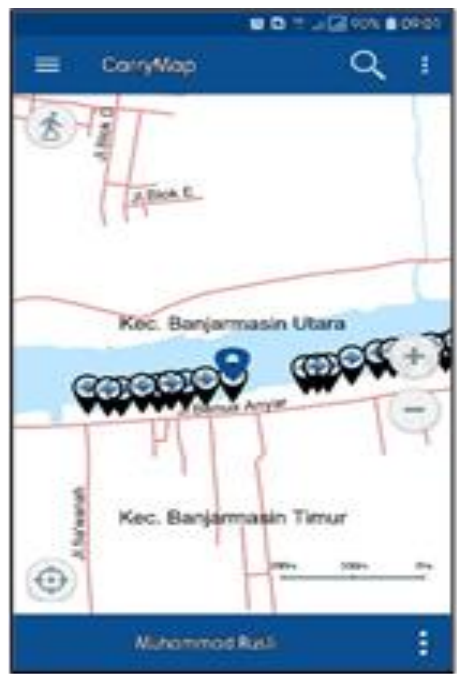

Gambar 5. Hasil pencarian 
Selain melakukan pencarian sesuai tema (keramba apung) peta portable ini juga dapat melakukan pencarian nama jalan diseluruh kota Banjarmasin. Untuk menuju lokasi keramba ataupun jalan yang ditentukan, kita dapat menggunakan feature GPS yang disediakan aplikasi CarryMap sehingga kita dapat dengan mudah menentukan arah pencarian karena posisi yang ditampilkan adalah titik keberadaan saat ini (real time) dari smart phone kita.

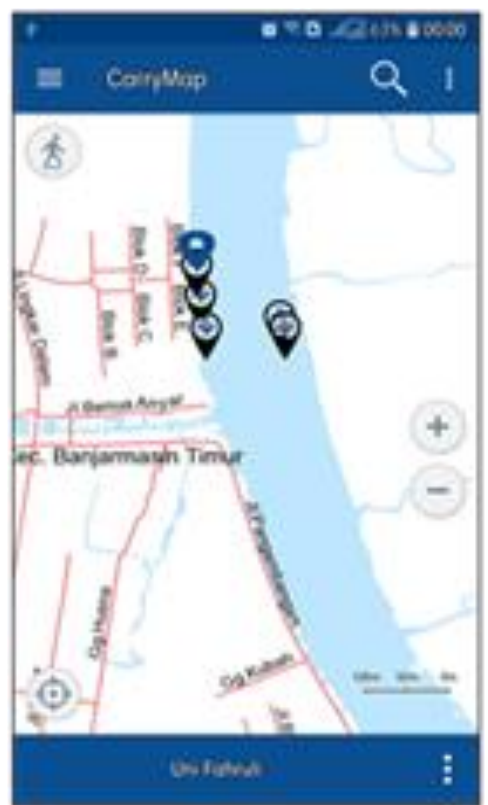

Gambar 6. pencarian secara langsung dengan pembesaran

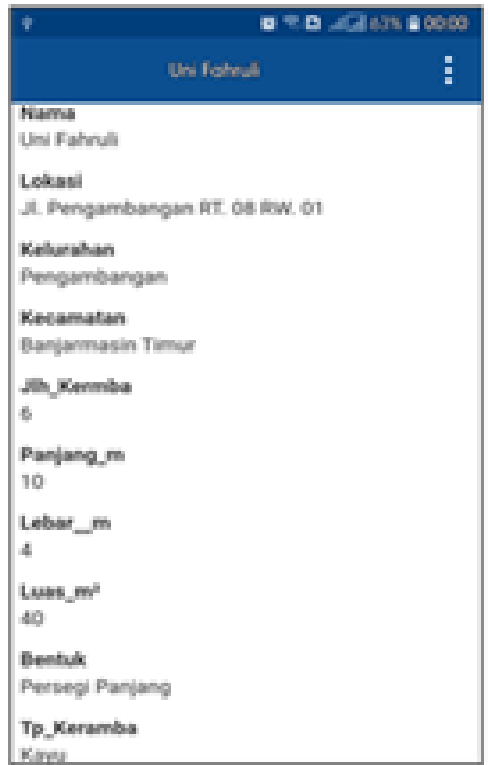

Gambar 7. data atribut dari titik terpilih.

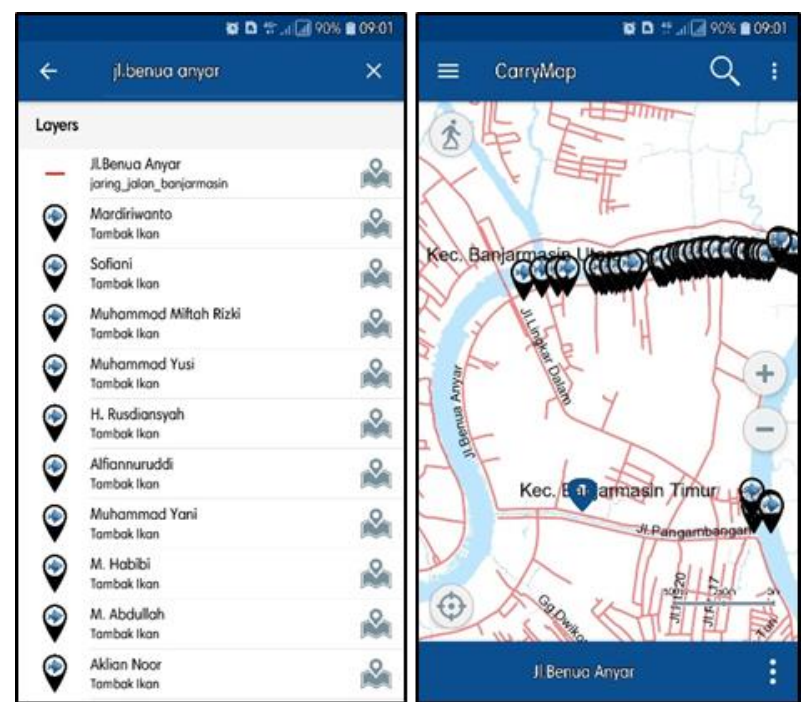

Gambar 8. Feature dari aplikasi CarryMap pencarian jalan dan menggunakan GPS

\section{PENUTUP}

\section{Kesimpulan}

Penelitian ini menghasilkan peta tematik dengan judul Persebaran Keramba Budidaya Ikan Apung Berbasis Android Smart phone Di Sepanjang Sungai Martapura Kota Banjarmasin.

Aplikasi ini memungkinkan kita menampilkan peta secara offline di smart phone tetapi dapat berintegrasi dengan GPS dan dapat dimanipulasi oleh penggunanya secara langsung

\section{Saran}

Peta portabel yang dihasilkan sudah dilengkapi dengan peta jaringan jalan dan sungai di kota Banjarmasin yang cukup lengkap, sehingga memungkinkan untuk memanfaatkan peta dasar tersebut untuk obyek penelitian lainnya. Seperti sebaran MCK/Jamban yang masih ada disepanjang sungai Martapura, data tersebut dapat digunakan pemerintah untuk mengontrol dan untuk keperluan studi kaitannya dengan isu lingkungan dan kebersihan air sungai.

\section{REFERENSI}

[1] D. Setyawan, A. Linai Nugraha, and B. Sudarsono, "Analisis Potensi Desa Berbasis Sistem Informasi Geografis," J. Geod. Undip, vol. 7, no. 4, 2018.

[2] G. F. Mandias, "Analisis Pengaruh Pemanfaatan Smartphone Terhadap Prestasi Akademik Mahasiswa Fakultas Ilmu Komputer Universitas Klabat," CogITo Smart J., vol. 3, no. 1, 2017. 
[3] Kemendikbud, "Hasil Pencarian - KBBI Daring," Kementrian Pendidikan dan Kebudayaan. 2018.

[4] F. Ade Irawan et al., "Positif: Jurnal Sistem dan Teknologi Informasi PEMBUATAN PETA PORTABEL BERBASIS ANDROID SMART PHONE KAMPUS TERAKREDITASI DI KOTA BANJARMASIN," vol. 5, no. 1, pp. 22-27, 2019.

[5] M. Ilhami, A. Nugraha, and H. Firdaus, "VISUALISASI PETA FASILITAS PENUNJANG WISATA RELIGI KABUPATEN DEMAK MENGGUNAKAN APLIKASI CARRYMAP (STUDI KASUS MASJID AGUNG DEMAK DAN MAKAM KADILANGU)," J. Geod. Undip, vol. 6, no. 4, 2017. 